\title{
Allergic Potential and Immunotoxicity Induced by Topical Application of 1-Chloro-4-(Trifluoromethyl)Benzene (PCBTF) in a Murine Model
}

\author{
Jennifer Franko, Laurel G. Jackson, B. Jean Meade, and Stacey E. Anderson \\ Health Effects Laboratory Division, National Institute for Occupational Safety and Health (NIOSH), 1095 Willowdale Drive, \\ Morgantown, WV 26505-2888, USA \\ Correspondence should be addressed to Jennifer Franko, hfy0@cdc.gov
}

Received 11 January 2011; Accepted 11 March 2011

Academic Editor: Gordon L. Sussman

Copyright ( $) 2011$ Jennifer Franko et al. This is an open access article distributed under the Creative Commons Attribution License, which permits unrestricted use, distribution, and reproduction in any medium, provided the original work is properly cited.

The purpose of the studies in this paper was to evaluate the allergic potential, immunotoxicity, and irritancy of the occupationally relevant chemical, 1-chloro-4-(trifluoromethyl)benzene, also known as parachlorobenzotrifluoride (PCBTF), following dermal exposure in a murine model. Evaluation of the sensitization potential, conducted using the local lymph node assay (LLNA) at concentrations ranging from $50 \%$ to $100 \%$, identified a dose-dependent increase in lymphocyte proliferation with a calculated EC3 value of $53.1 \%$. While no elevations in total or specific IgE were observed after exposure to any concentration of the chemical, significant increases in IFN- $\gamma$ protein production by stimulated draining lymphoid cells were observed, indicating a T-cell-mediated response. Dermal exposure to PCBTF was not found to alter the immune response to a T-cell-dependant antigen. These results demonstrate that PCBTF has the potential to induce allergic sensitization following dermal exposure and based on LLNA results would be classified as a weak sensitizer.

\section{Introduction}

1-Chloro-4-(trifluoromethyl)benzene, a fluorinated toluene, also known as parachlorobenzotrifluoride (PCBTF), is a chemical used as an intermediate in a wide range of organic reactions for the synthesis of dyes, pharmaceuticals, pesticides, insecticides and herbicides [1]. It is primarily used as a solvent in commercial surface finishes, such as vapor degreasing, precision wipe cleaning, cold cleaning and electronics cleaning, and is manufactured in both pure and blended formulations based upon specific cleaning requirements $[2,3]$. It is also used as an ink solvent in the printing industry and is a component (5-12\%) of low volatile organic compound (VOC) compliant polyurethane finishes. PCBTF is not considered to be an air toxin or ozone depleter. It has therefore recently been considered exempt from VOC regulations [4], which has led to an increase in its use as a replacement for other solvents previously used in the manufacture of a variety of commercially-available paints, inks, and other products and finishes (Oxsol 100, Occidental Chemical Co.) [1].

PCBTF was recently nominated by the National Toxicology Program (NTP) for toxicological characterization due to its unknown chronic toxicity profile and changes in its industrial and consumer use [1]. In addition, its improper use or disposal may lead to an increase in public exposure outside of the occupational context. There are currently no Occupational Safety \& Health Administration (OSHA), National Institute for Occupational Safety and Health (NIOSH), or American Conference of Governmental Industrial Hygienists (ACGIH) limits regulating PCBTF exposure [1].

Although the health effects of PCBTF have not been thoroughly tested, epidemiological studies in workers have reported increases in respiratory and stomach cancers [5]. Animal studies investigating the health effects of PCBTF exposure are limited. In a 13-week inhalational study in rats, no changes were identified in any measured clinical chemistry parameter, at doses up to $252 \mathrm{ppm}$, and no adverse 


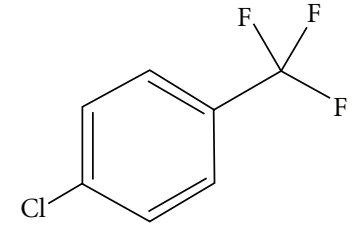

Figure 1: Chemical structure of PCBTF.

observations were recorded during exposures or during detailed weekly clinical evaluations [6]. Subchronic studies were negative for precancerous hematological changes and other histopathological indicators of carcinogenicity [7]. However, exposure to PCBTF did increase relative liver weights between dose groups. Subchronic inhalational and oral exposure to higher concentrations of PCBTF in rats produced clinical signs of toxicity that included salivation, tremors, altered hematological, and hepatocellular profiles [7]. These signs, however, were only noted at $1000 \mathrm{mg} / \mathrm{kg} /$ day, which is greatly outside of the range expected in a potential spill of PCBTF-containing paint products. PCBTF has low subchronic oral toxicity as well, and neither pathological nor adverse biochemical effects were found at doses up to $10 \mathrm{mg} / \mathrm{kg} /$ day, which have been described as the noobservable-effect level of PCBTF [8].

Although it is a primary route of occupational exposure, very few dermal exposure studies have been conducted on this chemical [2]. In addition, immunotoxicological studies are lacking. The recent increase in occupational use, along with the potential for dermal exposure warrants the evaluation of the immunotoxicity of PCBTF following dermal exposure.

\section{Material and Methods}

2.1. Test Articles and Chemicals. 1-Chloro-4-(trifluoromethyl)benzene (98\%) (PCBTF; Figure 1) [CAS no. 98-56-6], alpha-hexylcinnamaldehyde (HCA) [CAS no. 101-86-0], 2,4-dinitrofluorobenzene (DNFB) [CAS no. 70-34-8], toluene 2,4-diisocyanate (TDI, CAS 584-84-9) and cyclophosphamide [CAS no. 50-18-0] were all purchased from Aldrich Chemical Company, Inc. (Milwaukee, Wis).

2.2. Species Selection. Female $\mathrm{BALB} / \mathrm{c}$ and $\mathrm{B} 6 \mathrm{C} 3 \mathrm{~F} 1$ mice were used in these studies. BALB/c mice have a Th2 bias and are commonly used to evaluate potential IgEmediated sensitization. They were therefore used in the hypersensitivity studies $[9,10]$. B6C3F1 mice are the strain of choice for immunotoxicity studies and were used to evaluate the IgM response to SRBC [11]. The mice were purchased from Taconic (Germantown, NY) at 6-8 weeks of age. Upon arrival, the animals were allowed to acclimate for a minimum of 5 days. Each shipment of animals was randomly assigned to a treatment group, weighed, and individually identified via tail marking using a permanent marker. A preliminary analysis of variance on body weights was performed to ensure a homogeneous distribution of animals across treatment groups. The animals were housed at a maximum of 5 per cage in ventilated plastic shoebox cages with hardwood chip bedding. NIH-31 modified 6\% irradiated rodent diet (Harlan Teklad), and tap water was provided from water bottles, ad libitum. The temperature in the animal facility was maintained between 68 and $72^{\circ} \mathrm{F}$ and the relative humidity between 36 and $57 \%$. The light/dark cycle was maintained on 12-hour intervals. All animal experiments were performed in the AAALAC accredited NIOSH animal facility in accordance with an animal protocol approved by the Institutional Animal Care and Use Committee.

\subsection{Concentration Range Finding Studies. Concentration} range finding studies were performed to select the concentrations of PCBTF to be used for dermal exposures. BALB/c mice were exposed topically to acetone vehicle or increasing concentrations of PCBTF up to $100 \%$ in acetone on the dorsal surface of each ear ( $25 \mu \mathrm{L}$ per ear) for three consecutive days. Animals were allowed to rest for 2 days following the last exposure and then weighed and examined for signs of toxicity, such as loss of body weight, fatigue/lack of activity, and ungroomed fur. The maximum concentration selected for the subsequent studies was based on limits of toxicity.

2.4. Combined Local Lymph Node and Irritancy Assay. To determine the irritancy and sensitization potential of PCBTF, a combined local lymph node assay (LLNA) was conducted. PCBTF dosing concentrations (50-100\%) and vehicle (acetone) were selected based on solubility and preliminary concentration range finding studies. The LLNA was performed according to the method described in the ICCVAM Peer Review Panel report (1999) with minor modifications [12]. Briefly, mice (5 per group) were topically treated with acetone vehicle, increasing concentrations of PCBTF, or positive control (30\% alpha-hexylcinnamaldehyde; HCA) on the dorsal surface of each ear $(25 \mu \mathrm{L}$ per ear) once a day for three consecutive days. 2,4-dinitrofluorobenzene (DNFB) was used as a positive control for irritancy. Irritancy measurements were performed as previously described [13]. The thickness of the right and left ear pinnae of each mouse was measured using a modified engineer's micrometer (Mitutoyo Co.) before the first chemical administration and 24 hours following the final exposure. The mean percentage of ear swelling was calculated based on the following equation: [(mean postchallenge ear thickness - mean prechallenge ear thickness $) /$ mean prechallenge thickness $] \times 100$. Animals were allowed to rest for 2 days following the last exposure. On day 6 mice were injected intravenously, via the lateral tail vein, with $20 \mu \mathrm{Ci}{ }^{3} \mathrm{H}$-thymidine (Dupont NEN; specific activity $2 \mathrm{Ci} / \mathrm{mmol}$ ). Five hours after ${ }^{3} \mathrm{H}$-thymidine injection, animals were euthanized via $\mathrm{CO}_{2}$ inhalation, and the left and right superficial parotid draining lymph nodes (DLNs), located at the bifurcation of the jugular vein, were excised and pooled for each animal. Single cell suspensions were made and incubated overnight in 5\% trichloroacetic acid (TCA), and samples were counted using a Packard TriCarb 2500TR liquid scintillation analyzer (Perkin Elmer). Stimulation indices (SI) were calculated by dividing the mean disintegrations per minute (DPM) per test group by 
the mean DPM for the vehicle control group. EC3 values (concentration of chemical required to induce a 3 -fold increase over the vehicle control) were calculated based on the equations from Basketter et al. [14].

2.5. Phenotypic Analysis of Lymphocytes. Lymphocyte phenotypes were analyzed using flow cytometry as described by Manetz and Meade [15]. For the phenotypic analysis, mice were topically exposed to acetone or increasing concentrations of PCBTF (up to 100\%) on the dorsal surface of each ear ( $25 \mu \mathrm{L}$ per ear) once a day for four consecutive days. Animals were allowed to rest for 6 days after the final treatment and then euthanized on day 10 by $\mathrm{CO}_{2}$ inhalation. Animals were weighed and examined for gross pathology at the end of the experiment. The following organs were removed, cleaned of connective tissue and weighed: liver, spleen, kidneys, and thymus. DLNs (two nodes/animal/tube) and spleens were also collected separately in $3 \mathrm{~mL}$ PBS and were dissociated using the frosted ends of two microscope slides. Cell counts were performed using a Coulter Counter (Z2 model, Beckman Coulter), and $1 \times 10^{6}$ cells per sample were added to the wells of a 96-well plate. Cells were washed using staining buffer $(1 \%$ bovine serum albumin $/ 0.1 \%$ sodium azide in PBS) and then incubated with Fc block (clone 2.4G2). For IgE+/B220+ analysis, the cells were incubated with anti-CD45RA/B220 (PE, clone RA3-6B2) and anti-IgE antibodies (FITC, clone R-35-72) or appropriate isotype control diluted in staining buffer. For analysis of T-cell subsets, cells were incubated with anti-mouse CD3e antibody (APC, clone 145-2C11), antimouse CD4 antibody (FITC, clone RM4-5), and anti-mouse CD8a antibody (PE, clone 53-6.7) or the appropriate isotype controls diluted $1: 100$ in staining buffer. All antibodies and isotype controls were purchased from BD Pharmingen. Cells were then washed and incubated with propidium iodide (PI). After a final wash, cells were resuspended in staining buffer and analyzed with a Becton Dickinson FACSCalibur flow cytometer using a PI viability gate.

2.6. Total Serum IgE. For analysis of total IgE, PCBTF was tested at concentrations up to $100 \%$. Mice were treated with acetone, increasing concentrations of PCBTF, or, as a positive control, $1.5 \%$ TDI on the dorsal surface of each ear $(25 \mu \mathrm{L}$ per ear) once a day for four consecutive days. Animals were allowed to rest for 6 days after the final treatment and were euthanized on day 10 by $\mathrm{CO}_{2}$ inhalation. Following euthanasia, blood samples were collected via cardiac puncture. Sera were separated by centrifugation $(10 \mathrm{~min}$ at $10,000 \times \mathrm{g})$ and frozen at $-20^{\circ} \mathrm{C}$ for next day analysis of IgE by ELISA. A standard colorimetric sandwich ELISA was performed as previously described [16]. All antibodies and isotype controls were purchased from BD Pharmingen. In brief, 96-well flat bottom plates (Dynatech Immulon-2) were coated with purified monoclonal rat antimouse IgE antibody (clone R35-72; $2 \mu \mathrm{g} / \mathrm{mL}$, diluted in $0.05 \mathrm{M}$ carbonate-bicarbonate buffer, $\mathrm{pH}$ 9.6), sealed with plate sealers, and incubated overnight at $4^{\circ} \mathrm{C}$. The plates were washed 3 times with PBS/Tween 20 and then blocked for
1 hour with diluent (2\% fetal bovine serum (FBS; Hyclone Laboratories, Inc., Logan, Utah) and $0.05 \%$ sodium azide) at room temperature. Serum samples were diluted $1: 10$ in diluent and $\operatorname{IgE}$ control standards (mouse IgE antiTNP, clone C38-2) were prepared (highest concentration: $500 \mathrm{ng} / \mathrm{mL}$ ). The diluted serum samples and $\mathrm{IgE}$ control standards were then serially diluted $(1: 2)$ through 8 wells, added to the coated plates in a $100 \mu \mathrm{L}$ volume and incubated at room temperature for 1 hour. The plates were washed 3 times with PBS/0.05\% Tween 20. Biotin-conjugated rat antimouse IgE (clone R35-92; $2 \mu \mathrm{g} / \mathrm{mL}$ ) was added in a $100 \mu \mathrm{L}$ volume and plates were incubated at room temperature for 1 hour. The plates were then washed 3 times with PBS/0.05\% Tween 20. Streptavidin-alkaline phosphatase was added ( $100 \mu \mathrm{L}$ of a $1: 400$ in diluent) and plates were incubated for 1 hour at room temperature. P-Nitrophenyl phosphate (Sigma) was used as the alkaline phosphatase substrate and added to the plates in a $100 \mu \mathrm{L}$ volume. The plates were allowed to develop for up to 30 minutes at room temperature or until the optical density (OD) reading of the highest standard reached 3.0. Absorbance was determined using a Spectramax Vmax plate reader (Molecular Devices) at 405$605 \mathrm{~nm}$. Data analysis was performed using the IBM Softmax Pro 3.1 (Molecular Devices), and the IgE concentrations for each sample were interpolated from a standard curve using multipoint analysis.

\subsection{Analysis of Cytokine Production by Draining Lymph Node} Cells. To determine cytokine protein production by lymphocytes, DLNs of mice used for the analysis of total $\operatorname{IgE}$ were collected (two nodes/animal/tube) in $2 \mathrm{~mL}$ PBS and dissociated using the frosted ends of two microscope slides. Cell counts were performed using a Coulter Counter (Z1 model, Beckman Coulter), and cells were adjusted to $1 \times$ $10^{6}$ cells $/ \mathrm{mL}$ using sterile RPMI media containing $10 \%$ FBS. Cells were added to a 48 -well plate in a $500 \mu \mathrm{L}$ volume, stimulated with $\alpha$-CD3 and $\alpha$-CD28 $(2 \mu \mathrm{g} / \mathrm{mL}$ of each; BD Pharmingen) and incubated for 24 hours at $37^{\circ} \mathrm{C}$ and $5 \% \mathrm{CO}_{2}$. Supernatants were analyzed for IL-4 and IFN$\gamma$ production using an OptEIA ELISA kit purchased from $\mathrm{BD}$ Biosciences according to the manufacturer's instructions. Supernatants collected from each culture (2 stimulated and 2 unstimulated for each mouse) were added to the plates in triplicate along with serial dilutions of the standards. Plates were read at $450 \mathrm{~nm}$ [OD values for standards ranging from 0.77-1.93] using a SpectraMax M2 spectrophotometer (Molecular Devices). Cytokine concentration was extrapolated from the standard curve. The final data are expressed as the mean value generated when the concentration identified for the unstimulated cultures was subtracted from the value generated from the stimulated cultures for each mouse.

2.8. In Vivo IgM Response to the T-Cell-Dependent Antigen, $S R B C$. The primary IgM response to sheep red blood cells (SRBC) was enumerated using a modified hemolytic plaque assay of Jerne and Nordin [17]. B6C3F1 mice were dermally exposed to PCBTF (6-100\%) for 14 days $(25 \mu \mathrm{L} /$ ear). Four days prior to euthanasia (day 11), the mice were immunized 
with $7.5 \times 10^{7}$ SRBC by intravenous injection in a $200 \mu \mathrm{L}$ volume. All SRBC for these studies were drawn from a single donor animal (Lampire Laboratories, Pipersville, Penn). On the day of sacrifice, mice were euthanized by $\mathrm{CO}_{2}$ asphyxiation, body and organ weights were recorded and spleens were collected in $3 \mathrm{~mL}$ of Hanks Balanced Salt Solution (HBSS). Single cell suspensions of the spleens from individual animals were prepared in HBSS by disrupting the spleen between the frosted ends of microscopic slides. To identify the total number of spleen cells, $20 \mu \mathrm{L}$ of cells were added to $10 \mathrm{~mL}$ of isoton buffer $(1: 500)$ and two drops of Zap-o-globin were added to lyse red blood cells. Cells were then counted using a Coulter counter. $1: 30$ and $1: 120$ dilutions of spleen cells were made. One hundred $\mu \mathrm{L}$ of the dilutions were added to a test tube containing a $0.5 \mathrm{~mL}$ warm agar/dextran mixture (0.5\% Bacto-Agar, DIFCO; and $0.05 \%$ DEAE dextran, Sigma), $25 \mu \mathrm{L}$ of $1: 1$ ratio of SRBC suspension, and $25 \mu \mathrm{L}$ of $1: 4$ dilution (1 mL lyophilized) guinea pig complement (Cedarlane Labs). Each sample was vortexed, poured into a petri dish, covered with a microscope coverslip, and incubated for 3 hours at $37^{\circ} \mathrm{C}$. The plaques (representing antibody forming B-lymphocytes) were viewed and quantified after this incubation. Results were expressed as specific activity (IgM PFC per $10^{6}$ spleen cells) and total activity (IgM PFC per spleen).

2.9. Statistical Analysis. For analysis of the data generated from the described animal studies, the data were first tested for homogeneity using the Bartlett's Chi Square test. If homogeneous, a one-way analysis of variance (ANOVA) was conducted. If the ANOVA showed significance at $P<.05$ or less, the Dunnett's Multiple Range $t$ test was used to compare treatment groups with the control group. Linear trend analysis was performed to determine if PCBTF had exposure concentration-related effects for the specified endpoints. Statistical analysis was performed using Graph Pad Prism version 5.0 (San Diego, CA). Statistical significance is designated by $*(P \leq .05)$ and $* *(P \leq .01)$.

\section{Results}

3.1. In Vivo Studies Identified PCBTF to Be an Allergic Sensitizer. Dermal exposure to PCBTF was not found to be toxic at any concentration tested (data not shown). For this reason, concentrations of PCBTF up to $100 \%$ were tested in the subsequent studies. No ear swelling was observed in mice after dermal exposure to PCBTF (Figure 2), suggesting that PCBTF is nonirritating. DNFB $(0.03 \%)$ was used as a positive control for irritancy studies and resulted in an average significant increase of $84 \%$ in ear swelling after application (data not shown). In the LLNA, dose-dependent (Linear Trend test; $P<.01$ ) increases in DLN proliferation were observed after treatment with PCBTF, with counts from the $75 \%$ and $100 \%$ PCBTF exposed animals being significantly elevated over the vehicle control animals (Figure 3). SI values were 2.6, 5.3, and 5.3 for the $50 \%, 75 \%$, and $100 \%$ exposure groups, respectively. An EC3 value of 53.1\% (Figure 3) was calculated. HCA (30\%) was used as a positive control for

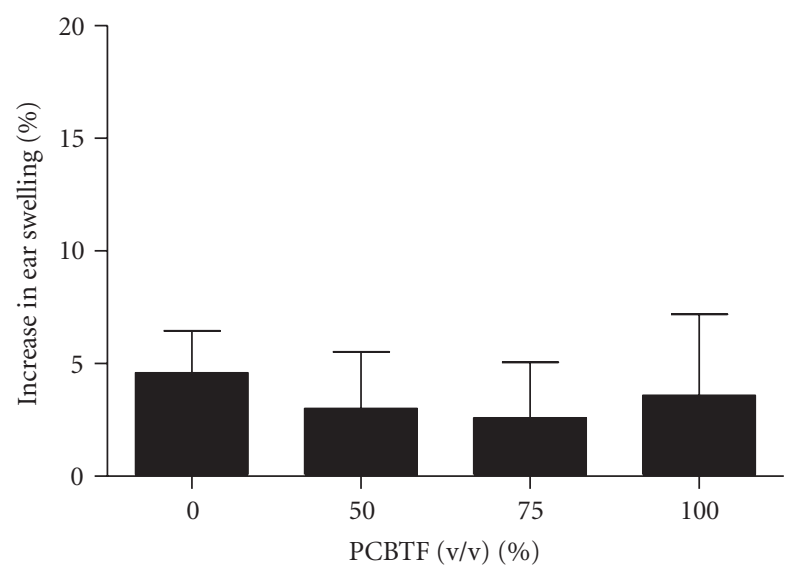

FIgURE 2: Ear swelling as a result of topical application of PCBTF. Analysis of irritation after topical application of PCBTF. Bars represent mean \pm SE of 5 mice (10 ears) per group.

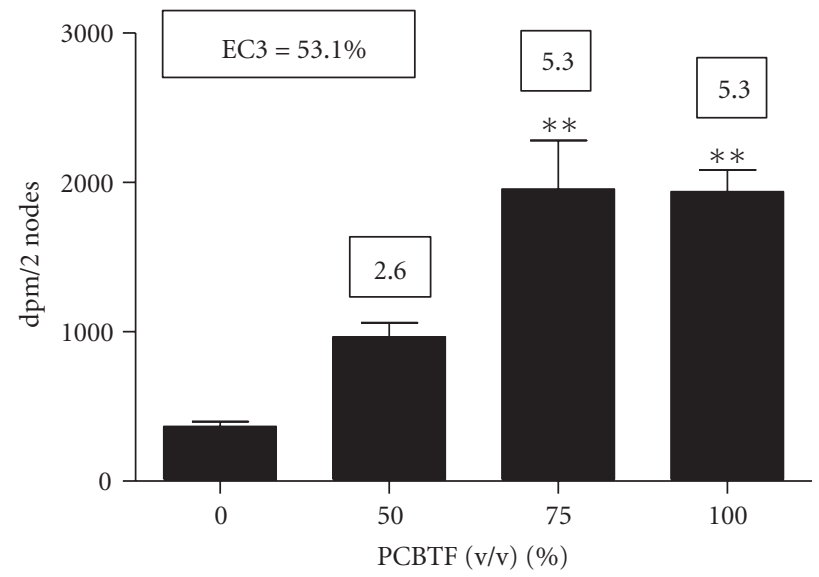

Figure 3: Allergic sensitization potential after dermal exposure to PCBTF. Analysis of the allergic sensitization potential of PCBTF using the LLNA. ${ }^{3} \mathrm{H}$-thymidine incorporation into draining lymph node cells of BALB/c mice following exposure to vehicle or concentration of PCBTF. Numbers in boxes appearing above the bars represent the stimulation indices for each concentration tested. Bars represent mean \pm SE of 5 mice per group. Levels of statistical significance are denoted $* *(P<.01)$ as compared to acetone vehicle.

these experiments and resulted in an average SI value of 24.5 (data not shown). Consistent with the LLNA results, PCBTF exposure also significantly elevated the cellularity of the DLN (Figure 4) following exposure to all concentrations.

\subsection{Exposure to PCBTF Did Not Induce an Increase in Local or Systemic IgE Levels. No changes in body or organ weights were observed after exposure to PCBTF for these studies (data not shown). The mechanisms of PCBTF sensitization were further investigated using phenotypic analysis of B220+ and IgE+B220+ expressing cells in the DLNs and spleen. No increases were observed in the $\mathrm{B} 220+$ cell or IgE $+\mathrm{B} 220+$ cell populations (Table 1) in the DLN or spleen. No changes in the percentage of CD4+ or CD8+ T cells in the DLN or}




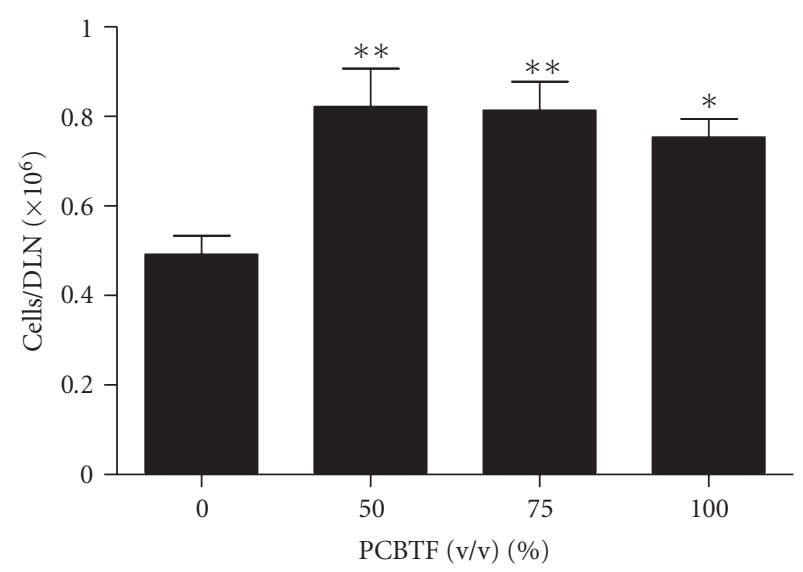

Figure 4: Increased cellularity of DLN after PCBTF exposure. Analysis of lymphocyte cellularity (cells/DLN) following exposure to PCBTF. Bars represent means \pm SE of 5 mice per group. Levels of statistical significance are denoted as $*(P \leq .05)$ and ${ }^{* *}(P \leq .01)$ as compared to acetone vehicle.

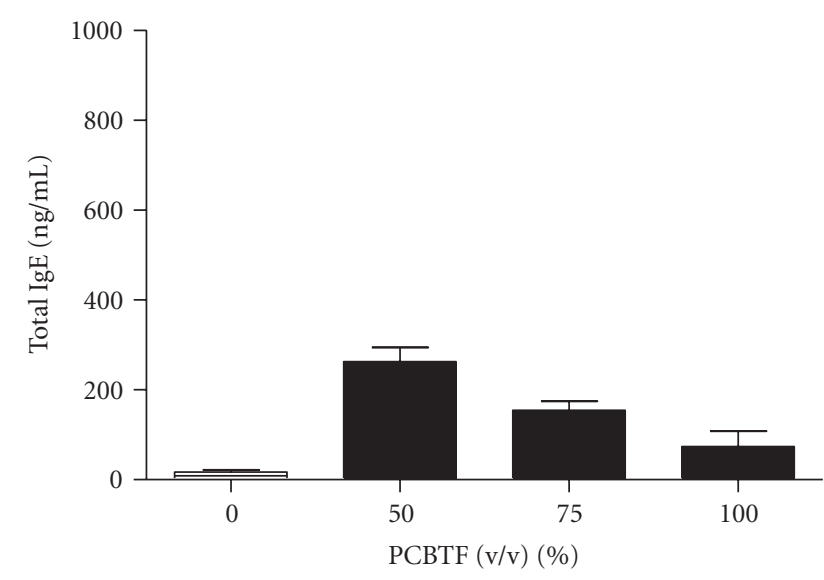

FIGURE 5: Lack of increase in serum IgE following PCBTF exposure. Analysis of total serum IgE after exposure to PCBTF. Bars represent means \pm SE of 5 mice per group.

spleen were observed after exposure to any concentration of PCBTF (data not shown). Consistent with the IgE+B220+ results, exposure to PCBTF did not elevate total serum $\operatorname{IgE}$ levels after exposure to any treatment groups (Figure 5). Dermal exposure to the respiratory sensitizer TDI $(1.5 \%)$ significantly elevated the $\mathrm{B} 220+(19.8 \pm 2.3 \%)$ cell population, IgE $+\mathrm{B} 220+(13.3 \pm 2.8 \%)$ cell populations, and total $\operatorname{IgE}(1587 \pm 109 \mathrm{ng} / \mathrm{mL})$ levels (data not shown).

3.3. Exposure to PCBTF Increased Production of IFN- $\gamma$, but Not IL-4 by Stimulated DLN Cells. Levels of IL-4 and IFN- $\gamma$ cytokine production by stimulated draining lymphoid cells were analyzed to evaluate the effect of PCBTF exposure on Th1/Th2 balance. A dose-responsive (Linear Trend test; $P<.01)$ increase in IFN- $\gamma$ protein production by the DLN was observed after dermal exposure to PCBTF. Significant elevations in cytokine production were observed at PCBTF concentrations $50 \%$ and greater (Figure 6(a)). The maximum increase in INF- $\gamma$ protein expression was calculated to be $1,174 \pm 169 \mathrm{pg} / \mathrm{mL}$. No significant alterations in IL-4 production were detected at any dose concentration (Figure 6(b)). To confirm the lack of Th2 cytokine induction following PCBTF exposure, cytokine mRNA levels were also analyzed in the DLNs of dermally exposed animals. Consistent with the protein data, no increase in IL-4 or IL-13 expression was observed (data not shown). Dermal treatment with $1.5 \%$ TDI elevated IL-4 and IL-13 mRNA expression in the DLN and significantly enhanced IL-4 protein production by stimulated draining lymphoid cells $(496 \pm 20 \mathrm{pg} / \mathrm{mL})$ (data not shown). The T-cell-mediated sensitizer HCA (30\%) significantly elevated IFN- $\gamma$ expression $(2,122 \pm 67 \mathrm{pg} / \mathrm{mL})$ (data not shown).

3.4. Dermal Exposure to PCBTF Did Not Alter the IgM Response to SRBC. To evaluate immunosuppressive potential, the murine splenic IgM response to SRBC was examined following a 14-day exposure to PCBTF. No changes in total (PFC/spleen) or specific (PFC/10 $10^{6}$ cells) IgM antibody activity to SRBC were observed after exposure to any concentration of PCBTF (Figure 7). Animals exposed to the positive control, cyclophosphamide, had a significantly reduced specific spleen IgM response (67\%) and total IgM response (54\%) compared to the acetone control animals. No changes in body or organ weights were observed for these animals (data not shown).

\section{Discussion}

More than 13 million workers in the United States are potentially exposed to chemicals that can be absorbed through the skin. Dermal exposure to chemicals in the workplace has a great potential to affect immune function. Contact dermatitis is the second most commonly reported occupational illness responsible for up to $30 \%$ of all cases of occupational disease in industrialized nations [18]. This may result in considerable social and economic implications, including time off from work, loss of workplace productivity, reduced quality of life, and medical and worker's compensation costs, accounting for the loss of billions of dollars [19].

Results from these studies suggest that PCBTF is a weak T-cell-mediated sensitizer. This was evidenced by an increase in lymphocyte proliferation and IFN- $\gamma$ protein production by stimulated draining lymphoid cells, in the absence of elevations in markers of IgE-mediated sensitization, such as total IgE and IL-4 (mRNA and protein) production, following dermal exposure in mice. The EC3 value for PCBTF, $53.1 \%$, falls within the working concentration for this chemical, as it is used at concentrations up to $100 \%$ as a solvent and as a chemical intermediate in the production of other chemicals. This suggests a greater predicted risk for worker sensitization. Immune suppression and other immunotoxic effects were not observed after exposure to this chemical.

Although exposure can occur through inhalation and dermal contact during its production and use [2], there 


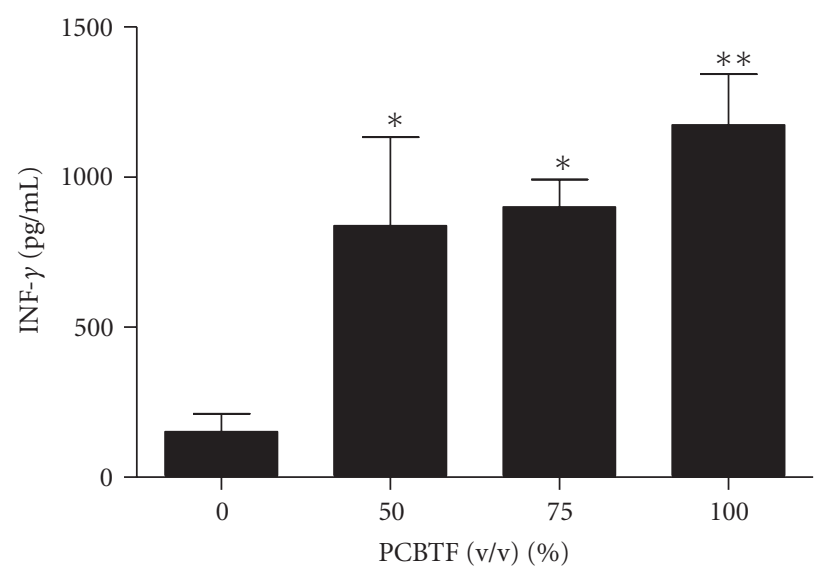

(a)

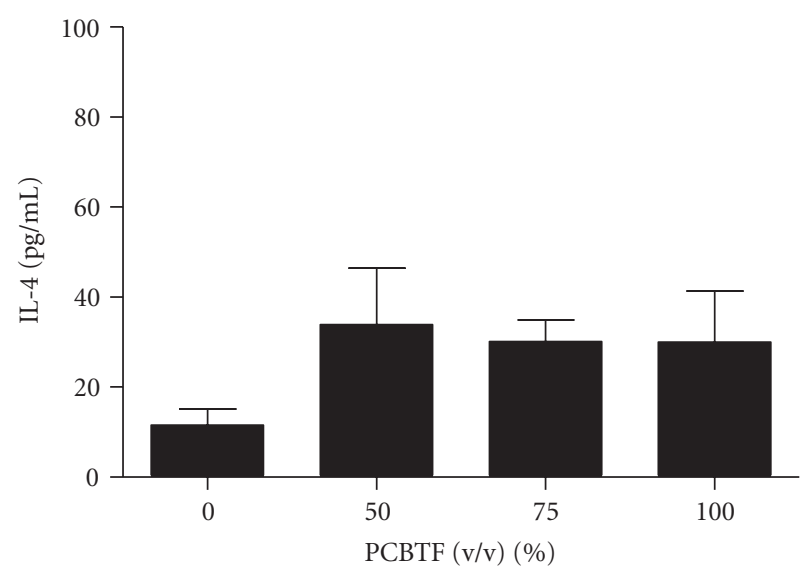

(b)

FIGURE 6: Increased IFN- $\gamma$ protein production by DLN. Analysis of cytokine protein expression (a) IL-4 and (b) IFN- $\gamma$ generated by stimulated DLN after dermal exposed to PCBTF. Bars represent mean fold change \pm SE of 5 mice per group. Levels of statistical significance are denoted as $*(P<.05)$ and $* *(P<.01)$ as compared to acetone vehicle.

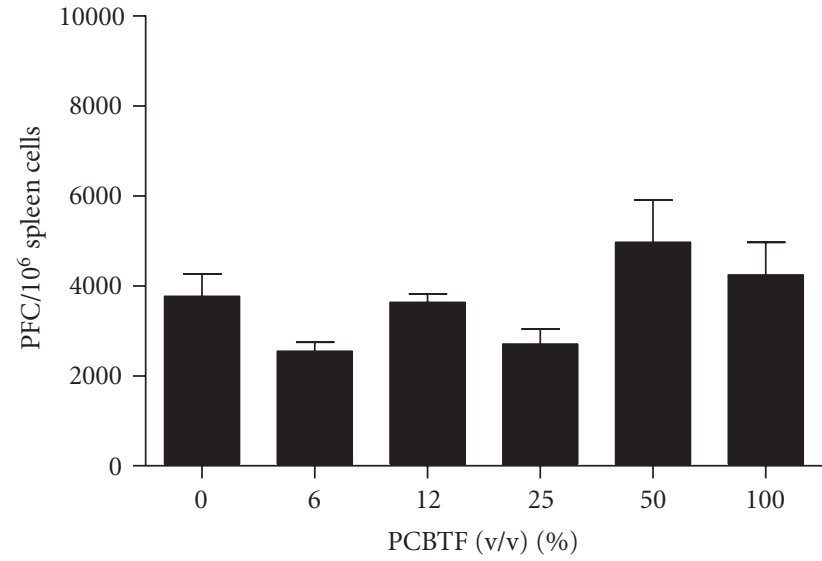

(a)

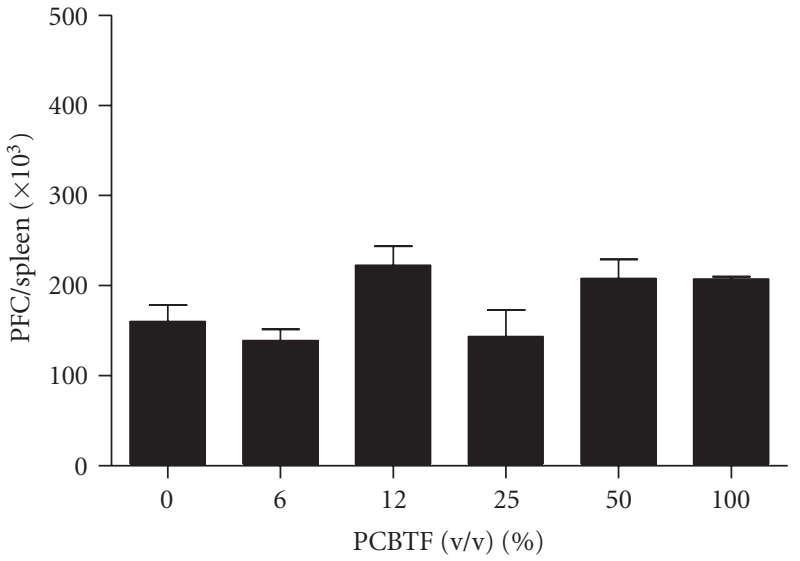

(b)

FIGURE 7: PCBTF exposure does not alter the IgM response to SRBC. Analysis of antibody producing spleen cells after a 14-day dermal exposure to PCBTF did not produce alternations in the total (a) and specific activity (b) IgM response to SRBC. Bars represent mean fold change \pm SE of 5 mice per group.

TABLE 1: Phenotypic analysis after in vivo PCBTF treatment.

\begin{tabular}{|c|c|c|c|c|}
\hline \multirow[t]{2}{*}{ Dose group } & \multicolumn{2}{|c|}{ IgE+B220+ (\% lymphocyte population $)$} & \multicolumn{2}{|c|}{ B220+ (\% lymphocyte population) } \\
\hline & $\%$ & Cells $\times 10^{6}$ & $\%$ & Cells $\times 10^{6}$ \\
\hline \multicolumn{5}{|l|}{ DLN } \\
\hline Acetone & $1.1 \pm 0.3$ & $0.09 \pm 0.02$ & $11.5 \pm 1.9$ & $1.1 \pm 0.16$ \\
\hline \multicolumn{5}{|l|}{ PCBTF } \\
\hline $50 \%$ & $4.5 \pm 2.1$ & $0.13 \pm 0.02$ & $14.0 \pm 3.1$ & $2.0 \pm 0.53$ \\
\hline $75 \%$ & $3.5 \pm 0.4$ & $0.12 \pm 0.02$ & $12.6 \pm 0.9$ & $1.8 \pm 0.24$ \\
\hline $100 \%$ & $2.4 \pm 0.6$ & $0.14 \pm 0.01$ & $12.0 \pm 1.4$ & $1.8 \pm 0.23$ \\
\hline \multicolumn{5}{|l|}{ Spleen } \\
\hline Acetone & $4.2 \pm 2.4$ & $2.1 \pm 1.01$ & $43.4 \pm 4.7$ & $2.3 \pm 1.06$ \\
\hline \multicolumn{5}{|l|}{ PCBTF } \\
\hline $50 \%$ & $4.7 \pm 2.5$ & $2.2 \pm 1.33$ & $38.9 \pm 1.8$ & $1.7 \pm 1.12$ \\
\hline $75 \%$ & $1.4 \pm 0.1$ & $1.7 \pm 1.58$ & $42.6 \pm 1.7$ & $1.9 \pm 0.96$ \\
\hline $100 \%$ & $2.2 \pm 0.9$ & $2.1 \pm 0.98$ & $40.1 \pm 1.4$ & $2.1 \pm 1.21$ \\
\hline
\end{tabular}


are no standards in place to limit occupational exposure to PCBTF [1]. For occupational exposures, an 8-hour timeweighted average (TWA) permissible exposure level of 20 ppm has been suggested by the Kowa American Corporation, the United States chemical importation company that has renominated PCBTF for toxicological evaluation $[1,6]$. In additional to occupational exposure, there is also the potential for exposure of the general public through PCBTFcontaining products and PCBTF in and around ground water [20]. Detectable levels of PCBTF have been identified in workers $(<1 \mathrm{ppm})$ as well as wildlife $(0.17-2.0 \mathrm{ppm})[21,22]$.

PCBTF is a halogenated solvent. These types of solvents are usually considered more toxic to humans and usually capable of causing greater environmental damage. Examples of other halogenated solvents include trichloroethylene, tetrachloroethylene, 1,1,1-trichloroethane, carbon tetrachloride, and dichloromethane. The majority of these solvents are classified as carcinogens and central nervous system depressants and can enter the body through respiratory or dermal exposure [23]. In addition to the effects to the central nervous system, workplace exposure to many of these solvents have been associated with toxic effects in the liver and kidney [24], as well as immune cell activation [25-31]. The effects of PCBTF exposure on immune parameters are consistent with those for other halogenated solvents, such as trichloroethylene, which has been shown to enhance activation markers on and IFN- $\gamma$ secretion by splenic CD4+ T-cells [25-27]. Enhanced T-cell activation due to trichloroethylene exposure has been demonstrated to enhance autoimmunerelated responses in both humans and mouse models [28, 29 ]. Due to the wide range of health effects associated with halogenated solvent exposure, occupational exposure limits have been set for these compounds, which have resulted in more stringent ventilation controls and personal protective equipment use by workers.

\section{Conclusion}

These are the first studies to indentify the sensitization potential of PCBTF following dermal exposure. Results from these studies indicate the importance of avoiding dermal contact with PCBT, due to its potential to function as a T-cellmediated sensitizer and encourages the need to determine appropriate PPE to prevent worker exposure.

\section{Disclosure}

The findings and conclusions in this report are those of the authors and do not necessarily represent the views of the National Institute for Occupational Safety and Health, Centers for Disease Control and Prevention.

\section{References}

[1] NTP, National Toxicology Program, Chemical Information Profile for 1-Chloro-4-(trifluoromethyl)benzene. National Institute of Environmental Health Sciences, Research Triangle Park, NC, USA, 2009.
[2] HSDB, "Hazardous Substances Data Bank. 1-Chloro-4(trifluoromethyl)benzene," HSDB Record No. 4251, February 2003, http://toxnet.nlm.nih.gov/cgi-bin/sis/search/f?./temp/ $\sim$ CkwdFP:4.

[3] J. J. Maul, P. J. Ostrowski, G. A. Ublacker, B. Linclau, and D. P. Curran, "Benzotrifluoride and derivatives: useful solvents for organic synthesis and fluorosynthesis," Topics in Current Chemistry, vol. 206, pp. 79-105, 1999.

[4] EPA, U.S., "National volatile organic comound emissin standards for aerosol coatings," Federal Register, vol. 74, no. 62, pp. 14941-14949, 2009.

[5] OCC, Occidental Chemical Corporation. Initial submission: mortality patterns of workers int he Niagara Plant (final report on mixtures of chemical substances) with attachments and cover letter dated 022192. TSCATS [Unpublished Health and Safety Studies submitted to EPA]. U.S. EPA/OPTS Public Files. Microfiche No. 0537001. Document No. 88-920001103. Record from Biblioline Basic, ECIS Record ID: TS-045214; abstract from TSCATS Low Detail Report link available at U.S. EPA, 1983, http://yosemite.epa.gov/oppts/epatscat8.nsf/ ReportSearchView/915F0B8E49E020F185257252006EAB2A.

[6] P. E. Newton, H. F. Bolte, W. R. Richter, M. B. Akinsanya, J. B. Knaak, and L. W. Smith, "Inhalation toxicity, neurotoxicity, and toxicokinetic studies of p-chlorobenzotrifluoride," Inhalation Toxicology, vol. 10, no. 1, pp. 33-48, 1998.

[7] Hooker Chemical Company, "Acute oral toxicity (LD50) in albine rats," TSCATS [Unpublished Health and Safety Studies submitted to EPA]. U.S. EPA/OPTS Public Files. Microfiche No. 0508138. Document No. 40-7952012, 1979.

[8] A. Macri, C. Ricciardi, A. V. Stazi et al., "Subchronic oral toxicity of 4-chloro-alpha, alpha, alpha-trifluorotoluene in Sprague-Dawley rats," Food and Chemical Toxicology, vol. 25, no. 10, pp. 781-786, 1987.

[9] K. J. Klink and B. J. Meade, "Dermal exposure to 3-amino5-mercapto-1,2,4-triazole (AMT) induces sensitization and airway hyperreactivity in BALB/c mice," Toxicological Sciences, vol. 75, no. 1, pp. 89-98, 2003.

[10] M. R. Woolhiser, A. E. Munson, and B. J. Meade, "Comparison of mouse strains using the local lymph node assay," Toxicology, vol. 146, no. 2-3, pp. 221-227, 2000.

[11] M. I. Luster, C. Portier, D. G. Pait et al., "Risk assessment in immunotoxicology. I. Sensitivity and predictability of immune tests," Fundamental and Applied Toxicology, vol. 18, no. 2, pp. 200-210, 1992.

[12] NIEHS, "National Institute of Environmental Health Sciences; the murine local lymph node assay: a test method for assessing the allergic contact dermatitis potential of chemicals/ compounds," Federal Register, vol. 64, pp. 14006-14007, 1999.

[13] M. R. Woolhiser, A. E. Munson, and B. J. Meade, "Role of sensitization routes in the development of type I hypersensitivity to natural rubber latex in mice," American Journal of Industrial Medicine, vol. 36, no. 1, pp. 139-141, 1999.

[14] D. A. Basketter, L. J. Lea, A. Dickens et al., "A comparison of statistical approaches to the derivation of EC3 values from local lymph node assay dose responses," Journal of Applied Toxicology, vol. 19, no. 4, pp. 261-266, 1999.

[15] T. S. Manetz and B. J. Meade, "Development of a flow cytometry assay for the identification and differentiation of chemicals with the potential to elicit irritation, IgE- mediated, or T cellmediated hypersensitivity responses," Toxicological Sciences, vol. 48, no. 2, pp. 206-217, 1999.

[16] J. E. Butler, "Enzyme-linked immunosorbent assay," Journal of Immunoassay, vol. 21, no. 2-3, pp. 165-209, 2000. 
[17] N. K. Jerne and A. A. Nordin, "Plaque formation in agar by single antibody-producing cells," Science, vol. 140, no. 3565, p. 405, 1963.

[18] B. D. Lushniak, "The importance of occupational skin diseases in the United States," International Archives of Occupational and Environmental Health, vol. 76, no. 5, pp. 325-330, 2003.

[19] C. A. Burnett, B. D. Lushniak, W. McCarthy, and J. Kaufman, "Occupational dermatitis causing days away from work in U.S. private industry, 1993," American Journal of Industrial Medicine, vol. 34, no. 6, pp. 568-573, 1998.

[20] D. Botta and E. Mantica, "Micropollutants migration from ion-exchange resins into water," Water Research, vol. 33, no. 4, pp. 1054-1064, 1999.

[21] EPA, U.S., "4-chlorobenzotrifluoride; decision not to test," Federal Register, vol. 50, no. 292, pp. 42216-42221, 1985.

[22] M. P. Yurawecz, "Gas-liquid chromatographic and mass spectrometric indentification of chlorinated trifluorotoluene residues in Niagara River fish," Journal of the Association of Official Analytical Chemists, vol. 62, no. 1, pp. 36-40, 1979.

[23] NIOSH, "Control of Exposure to Perchloroethylene in Commercial Drycleaning," Hazard Controls: Publication 97-157. National Institute for Occupational Safety and Health, 1997, http://www.cdc.gov/niosh/hc19.html.

[24] R. O. Recknagel, "Carbon tetrachloride hepatotoxicity," Pharmacological Reviews, vol. 19, no. 2, pp. 145-208, 1967.

[25] K. M. Gilbert, J. M. Griffin, and N. R. Pumford, "Trichloroethylene activates CD4+ T cells: potential role in an autoimmune response," Drug Metabolism Reviews, vol. 31, no. 4, pp. 901916, 1999.

[26] J. M. Griffen, S. J. Blossom, S. K. Jackson, K. M. Gilbert, and N. R. Pumford, "Triethylen accelerates an autoimmune response by Th1 T cell actiation in MRL+/+ mice," Immunopharmacology, vol. 46, pp. 123-137, 2000.

[27] J. M. Griffin, K. M. Gilbert, L. W. Lamps, and N. R. Pumford, "CD4 T-cell activation and induction of autoimmune hepatitis following trichloroethylene treatment in MRL $+/+$ mice," Toxicological Sciences, vol. 57, no. 2, pp. 345-352, 2000.

[28] I. Iavicoli, A. Marinaccio, and G. Carelli, "Effects of occupational trichloroethylene exposure on cytokine levels in workers," Journal of Occupational and Environmental Medicine, vol. 47, no. 5, pp. 453-457, 2005.

[29] G. S. Cooper, S. L. Makris, P. J. Nietert, and J. Jinot, "Evidence of autoimmune-related effects of trichloroethylene exposure from studies in mice and humans," Environmental Health Perspectives, vol. 117, no. 5, pp. 696-702, 2009.

[30] M. Seo, T. Yamagiwa, R. Kobayashi et al., "A small amount of tetrachloroethylene ingestion from drinking water accelerates antigen-stimulated allergic responses," Immunobiology, vol. 213, no. 8, pp. 663-669, 2008.

[31] D. Jírová, I. Šperlingová, M. Halašková, H. Bendová, and L. Dabrowská, "Immunotoxic effects of carbon tetrachloridethe effect on morphology and function of the immune system in mice," Central European Journal of Public Health, vol. 4, no. 1, pp. 16-20, 1996. 


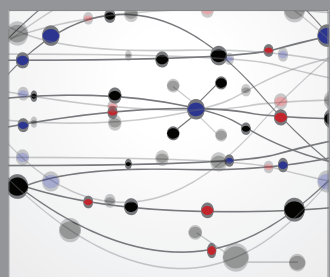

The Scientific World Journal
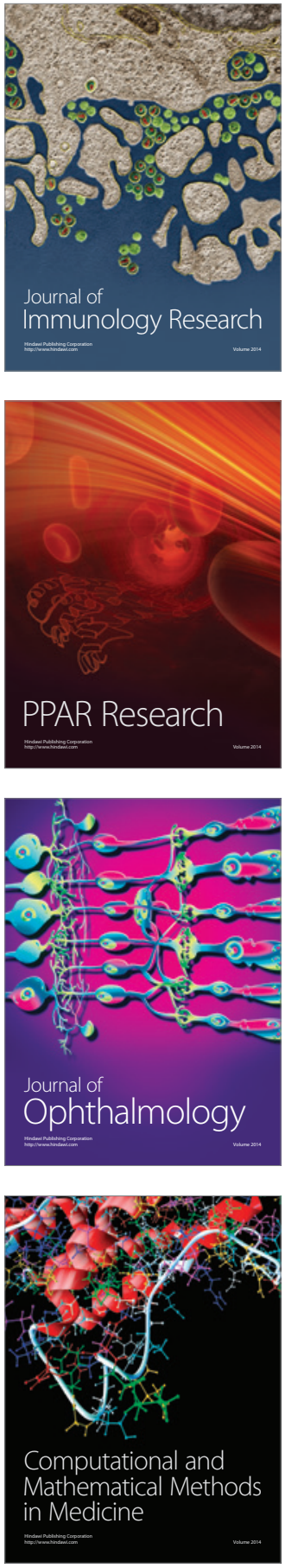

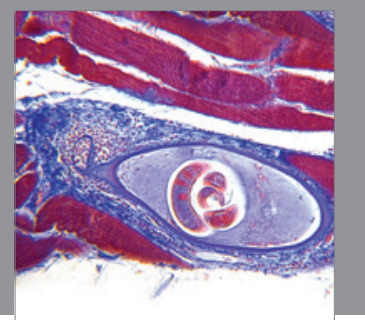

Gastroenterology

Research and Practice
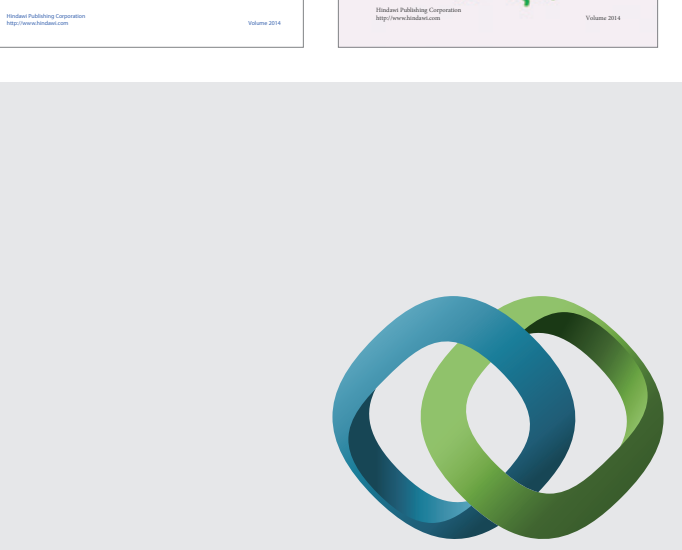

\section{Hindawi}

Submit your manuscripts at

http://www.hindawi.com
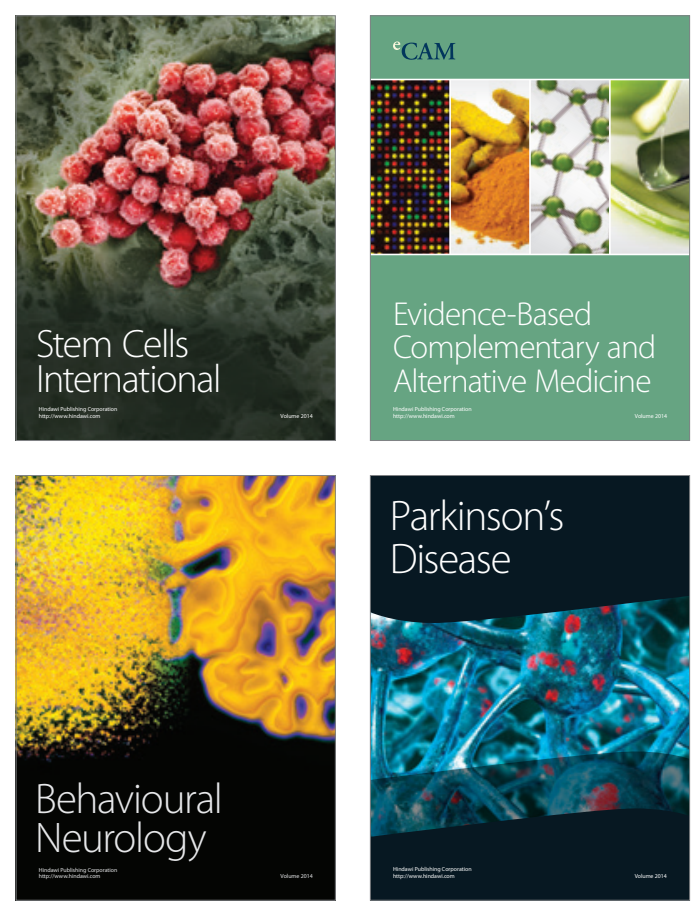

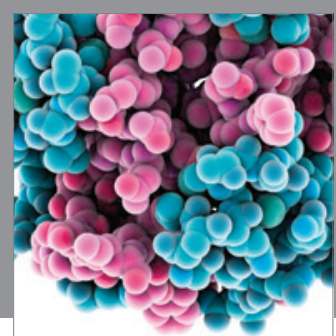

Journal of
Diabetes Research

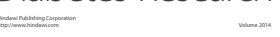

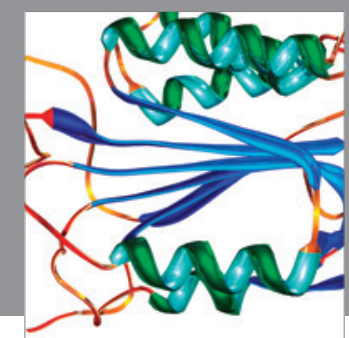

Disease Markers
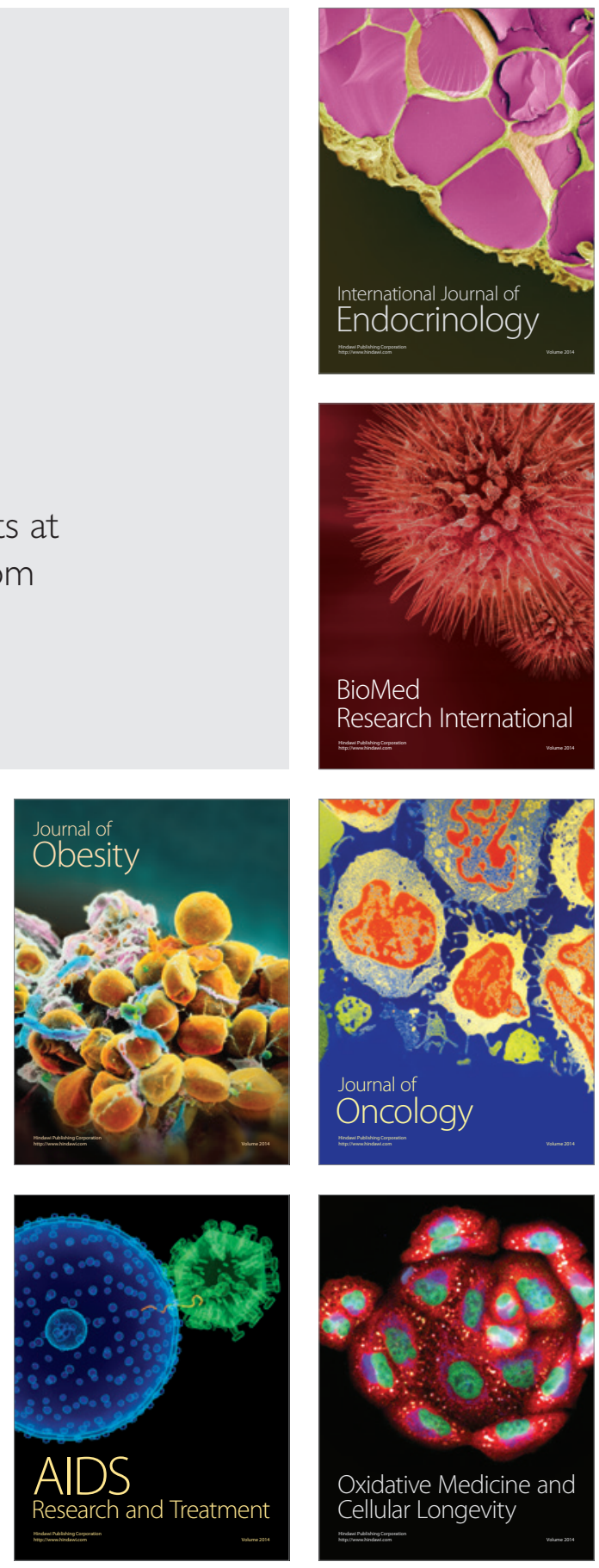